\title{
ASSESSMENT AND COMPARISON OF CARDIAC FUNCTION AND VOLUME STATUS USING BEDSIDE ECHOCARDIOGRAPHY IN CRITICALLY ILL PATIENTS WITH OTHER CONVENTIONAL METHODS
}

\author{
${ }^{1}$ Lecturer, Department of Anaesthesia, BRD Medical College, Gorakhpur. \\ ${ }^{2}$ Associate Professor, Department of Anaesthesia, BRD Medical College, Gorakhpur. \\ ${ }^{3}$ Resident, Department of Anaesthesia, BRD Medical College, Gorakhpur. \\ ${ }_{4}^{4}$ Lecturer, Department of Anaesthesia, BRD Medical College, Gorakhpur. \\ 5 Professor, Department of Anaesthesia, BRD Medical College, Gorakhpur. \\ ${ }^{6}$ Lecturer, Department of Anaesthesia, BRD Medical College, Gorakhpur. \\ 7 Professor, Department of Anaesthesia, BRD Medical College, Gorakhpur.
}

Priyanka Dwivedi1, Shahbaz Ahmad², Vivek Pushp³, Narendra Deo4, Satish Kumar ${ }^{5}$, Santosh Sharma6, Raka Rani ${ }^{7}$

\section{ABSTRACT}

\section{BACKGROUND}

CHF is a common cause of respiratory failure in ICU patients, though is a big challenge to differentiate it from other causes. Inaccurate diagnosis places these patients at higher risk of morbidity and mortality. Bedside echocardiography by emergency physician offers a rapid, non-invasive and inexpensive tool to assess patient's cardiac function and its role in ongoing disease process.

\section{MATERIALS AND METHODS}

30 critically ill patients admitted in ICU were assessed and categorised as CHF +ve and CHF -ve using Framingham's criteria. After initial stabilisation, all patients underwent bedside echocardiography and central venous catheterisation. CVP measurements were obtained at end expiration in supine position. LVEF was estimated with the M-mode LV dimensional/Teichholz method using parasternal long axis view. Transverse diameter of the IVC was measured at subxiphoid level at end-inspiration and end-expiration.

\section{RESULTS}

According to Framingham's criteria, 14 patients were CHF +ve and 16 CHF -ve. ECHO detected CHF in 12 patients (True positive) with positive predictive value of $92.30 \%$ and 15 patients did not have CHF (true negative) with negative predictive value of $84.21 \%$. Accuracy was found to be $90 \%$ and sensitivity $85.71 \%$. IVC diameter variability was significantly higher in CHF negative group (p value $=<.001$ ). There is high correlation of IVC diameter variability with CVP, $r=-.922$ in CHF positive group.

\section{CONCLUSION}

In Intensive care, bedside ECHO improves ability of intensivists to evaluate LVEF and volume status of the patient and helps in determining the cause of respiratory failure.

\section{KEYWORDS}

Echocardiography, CHF, IVC Diameter Variability, CVP.

HOW TO CITE THIS ARTICLE: Dwivedi P, Ahmad S, Pushp V, et al. Assessment and comparison of cardiac function and volume status using bedside echocardiography in critically ill patients with other conventional methods. J. Evolution Med. Dent. Sci. 2016;5(85): 6318-6322, DOI: $10.14260 /$ Jemds/2016/1427

\section{BACKGROUND \\ Correct and timely diagnosis of prevailing haemodynamic process is of utmost importance and the physical examination and vital signs alone are often unreliable. Moreover, congestive heart failure is extremely prevalent in the emergency department population and more than half of patients with moderate-to-severe systolic dysfunction have never been diagnosed with heart failure. Underestimation or overestimation of intravascular volume needs can be severely deleterious and direct evaluation of gross cardiac function may be needed to identify impaired systolic function, cardiac filling, signs of acute pulmonary hypertension or volume status.}

Financial or Other, Competing Interest: None.

Submission 01-09-2016, Peer Review 11-10-2016,

Acceptance 17-10-2016, Published 22-10-2016.

Corresponding Author:

Dr. Priyanka Dwivedi,

Type 4/21, BRD Medical College,

Gorakhpur-273013.

E-mail: drpriyad1111@gmail.com

DOI: $10.14260 /$ jemds $/ 2016 / 1427$

\section{(c) $($ ) $\$$}

It is clinically a big challenge to differentiate the heart failure from other causes of respiratory failure in ICU patients. A helpful history is often not obtainable in an acutely ill patient and dyspnoea a key symptom of CHF may also be a nonspecific finding in obese, elderly or critically ill patients. Routine laboratory values, $\mathrm{x}$-rays and electrocardiogram are also not accurate enough to always make the appropriate diagnosis. ${ }^{1}$

Bedside echocardiography by emergency physician offers a rapid, non-invasive and inexpensive method to determine the role that the patient's systolic cardiac function may be playing in their disease process and has been proposed as a readily accessible non-invasive modality in critically ill patients. ${ }^{2,3}$ Besides the diagnosis of heart failure, assessment of left ventricular function can help distinguish between cardiac and other aetiologies of undifferentiated hypotension or shock and may offer useful information on cardiac function and volume status. ${ }^{4,5}$

The aim of this comparative study was to compare the efficacy and sensitivity of bedside TTE (Transthoracic echocardiography) over clinical methods of detecting cardiac failure and to compare the volume status of IVC (Inferior Vena 
Cava) pressure by TTE to CVP (Central Venous Pressure) measurement.

\section{MATERIALS AND METHODS}

The present study was conducted on 30 patients of age 20-60 years, admitted to the intensive care unit presenting with primary or secondary respiratory distress. After permission from Ethical Committee, informed consent was taken from all patients. Framingham's criteria were used to determine the presence or absence of clinical CHF, which has high sensitivity and moderate specificity and patients were divided into $\mathrm{CHF}$ positive and CHF negative groups. Exclusion criteria for the study were age $<20$ years and $>60$ years, pregnancy, patients with arrhythmias, patients with contraindication to central venous catheterisation and any obvious traumatic cause. A detailed clinical history was taken from each patient and a thorough clinical examination was done including cardiovascular system and respiratory system. Urine output and other parameters included in the study were monitored continuously. Relevant investigations like Hb, TLC, DLC, S. urea, S. creatinine, LFT, coagulation profile, ABG, blood sugar, S. electrolytes, chest $\mathrm{x}$-ray, ECG, etc. was done in all patients.

All patients were stabilised haemodynamically. Central venous catheterisation was done and CVP monitored. In all the patients CVP measurement was done at end expiration in supine position. Vasopressors were added if required and artificial ventilation was instituted when required.

Echocardiographic examinations were conducted with a P10/8-4 MHz echo probe of portable Sonosite-Micromax-5 Ultrasonographic unit in all the patients. Left Ventricular Ejection Fraction (LVEF) was estimated with the M-mode LV dimensional or Teichholz method. It was performed using parasternal long axis view, with images obtained in M mode. Normal range of LVEF is $50-75 \%$. The measurements made were analysed by the biostatistical software of the echocardiography machine and patients were categorised as having ejection fraction $<25 \%, 25-34 \%, 35-49 \%$ and $>50 \%$.

Transverse and longitudinal diameter of the IVC were measured at subxiphoid level with subxiphoid long axis view at end inspiration and end expiration for estimation of volume status and patients were categorised as having diameter variability of IVC as $15 \%, 16-40 \%$ and $>40 \%$. All patients were studied in strictly supine position without mobilisation to left lateral position.

Student ' $t$ ' test was used for statistical analysis of pulse and blood pressure using online graph pad prism software and Chi square test was used for statistical analysis of CVP and IVC diameter variability using online quantpsy chi square software.

\section{RESULTS}

Out of total 30 patients assessed, 14 were supposed to have CHF positive and 16 CHF negative according to Framingham's criteria. Echocardiography detected $\mathrm{CHF}$ in 12 patients successfully (true positive) with positive predictive value $92.30 \%$, while 1 patient was detected as false positive. Echocardiography confirmed that 15 patients did not have CHF (true negative) with negative predictive value of $84.21 \%$ and 2 patients were found to be CHF negative who were $\mathrm{CHF}$ positive according to Framingham's criteria (false negative).

Out of total 14 CHF positive patients 13 needed inotropic support, while in CHF negative group 12 patients out of 16 required inotropic support and 4 did not. Dopamine and Dobutamine were the vasopressors of choice to correct hypotension. More number of patients in CHF positive group required artificial ventilation in the form of invasive ventilation. It can be attributed to poor condition of the patients. Ventilatory mode was chosen accordingly to maintain $\mathrm{SPO}_{2}$ within normal limit.

There was tachycardia and hypotension in all the patients; however, the mean pulse rate in CHF positive patients was significantly high $(\mathrm{p}=<0.001)$ and systolic blood pressure was significantly low $(\mathrm{p}=<0.001)$.

Out of total 14 CHF positive patients, CVP was found to be 8-12 mmHg in 2 (14.28\%) patients and was >12 $\mathrm{mmHg}$ in 12 $(85.71 \%)$ patients. Out of total 16 CHF negative patients, CVP was found to be < $8 \mathrm{mmHg}$ in $1(6.25 \%)$ patients, $8-12 \mathrm{mmHg}$ in $14(87.5 \%)$ patients and $>12 \mathrm{mmHg}$ in $1(6.25 \%)$ patients. Value of CVP was significantly higher in CHF positive group ( $p$ value $=<.001$ ).

IVC diameter variability was significantly higher in CHF negative group ( $\mathrm{p}$ value $=<.001$ ), which means that these patients are more responsive to further fluid resuscitation. Pearson correlation coefficient was derived for IVC diameter variability and CVP in both CHF positive and CHF negative group, which showed strongly negative correlation between the two. In CHF positive group correlation coefficient was .922 $(\mathrm{r}=-.922)$ and in Table 3 CHF negative group it was .760 $(\mathrm{r}=-.760)$

Table 3 shows that out of total 14 CHF positive patients LVEF was < $25 \%$ in $2(14.28 \%)$ patients, $25-35 \%$ in 10 (71.42\%) patients, $36-50 \%$ in 1 (7.14\%) patient and was > $50 \%$ in $1(7.14 \%)$ patient, while in CHF negative group LVEF was $<25 \%$ in 0 patient, $25-35 \%$ in $1(6.25 \%)$ patient, $36-50 \%$ in $4(25 \%)$ and $>50 \%$ in $11(68.75 \%)$ patients.

For diagnosing $\mathrm{CHF}$ with bedside echocardiography in our study; a 2 x 2 contingency table was made showing number of patients having CHF according to Framingham's criteria and echocardiography. ECHO detected CHF in 12 patients successfully (true positive) and 1 patient as false negative; 15 patients did not have CHF (true negative) and 2 patients were found to be CHF negative who were $\mathrm{CHF}$ positive according to Framingham's criteria (false negative).

\section{Data from this Table showed the Following also}

a. Accuracy was found to be $90 \%$.

b. Sensitivity was found to be $85.71 \%$.

c. Specificity was found to be $93.75 \%$.

d. Positive predictive value was found to be $92.305 \%$.

e. Negative predictive value was found to be $88.23 \%$.

\begin{tabular}{|c|c|c|c|c|}
\hline & \multicolumn{2}{|c|}{ CHF - Positive } & \multicolumn{2}{c|}{ CHF - Negative } \\
\hline Age (in years) & No. & $\%$ & No. & $\%$ \\
$20-39$ & 6 & 42.85 & 13 & 81.25 \\
$40-60$ & 8 & 57.14 & 3 & 18.75 \\
\hline Sex & & & & \\
Male & 6 & 42.85 & 11 & 68.75 \\
Female & 8 & 57.14 & 5 & 31.25 \\
\hline Inotropic Support & & & & \\
Present & 13 & 92.85 & 12 & 75 \\
Absent & 1 & 7.14 & 4 & 25 \\
Ventilation & & & & \\
Venturi mask & 4 & 28.57 & 7 & 43.75 \\
Non-invasive & 1 & 7.14 & 2 & 12.50 \\
Invasive & 9 & 64.24 & 7 & 43.75 \\
\hline
\end{tabular}




\begin{tabular}{|c|c|c|}
\hline \multicolumn{3}{|c|}{ Table 1 } \\
\hline & CHF - Positive & CHF - Negative \\
\hline Mean Pulse Rate & $125 \pm 13.57$ & $96.18 \pm 14.76$ \\
\hline $\begin{array}{c}\text { Mean Systolic BP } \\
\text { (mmHg) }\end{array}$ & $87.5 \pm 8.60$ & $98 \pm 5.97$ \\
\hline $\begin{array}{c}\text { Mean Diastolic } \\
\text { BP (mmHg) }\end{array}$ & $60.07 \pm 11.44$ & $63.93 \pm 15.70$ \\
\hline $\begin{array}{c}\text { Mean BP } \\
\text { (mmHg) }\end{array}$ & $69.21 \pm 9.50$ & $72.55 \pm 11.59$ \\
\hline \multicolumn{3}{|c|}{ Table 2 } \\
\hline
\end{tabular}

\begin{tabular}{|c|c|c|c|c|}
\hline & \multicolumn{2}{|c|}{ CHF - Positive } & \multicolumn{2}{|c|}{ CHF - Negative } \\
\hline CVP (mmHg) & No. & $\%$ & No. & $\%$ \\
\hline$<8$ & 0 & 0 & 1 & 6.25 \\
\hline $8-12$ & 2 & 14.28 & 14 & 87.5 \\
\hline$>12$ & 12 & 85.71 & 1 & 6.25 \\
\hline $\begin{array}{c}\text { IVC Diameter } \\
\text { Variability } \\
<15 \% \\
16-40 \% \\
>40 \%\end{array}$ & $\begin{array}{c}11 \\
1 \\
2\end{array}$ & $\begin{array}{c}78.57 \\
7.14 \\
14.28\end{array}$ & $\begin{array}{c}1 \\
0 \\
15\end{array}$ & $\begin{array}{c}6.25 \\
0 \\
93.75\end{array}$ \\
\hline $\begin{array}{c}\text { LVEF } \\
<25 \% \\
25-35 \% \\
36-50 \% \\
>50 \%\end{array}$ & $\begin{array}{c}2 \\
10 \\
1 \\
1\end{array}$ & $\begin{array}{c}14.28 \\
71.42 \\
7.14 \\
7.14\end{array}$ & $\begin{array}{c}0 \\
1 \\
4 \\
11\end{array}$ & $\begin{array}{c}0 \\
6.25 \\
25 \\
68.75\end{array}$ \\
\hline $\begin{array}{c}\text { Other Cardiac } \\
\text { Abnormalities } \\
\text { WMA } \\
\text { DD } \\
\text { LVH } \\
\text { No abnormality }\end{array}$ & $\begin{array}{c}2 \\
0 \\
2 \\
10\end{array}$ & $\begin{array}{c}14.28 \\
0 \\
14.28 \\
71.42\end{array}$ & $\begin{array}{c}0 \\
1 \\
0 \\
15\end{array}$ & $\begin{array}{c}0 \\
6.25 \\
0 \\
93.75\end{array}$ \\
\hline & & & & \\
\hline
\end{tabular}

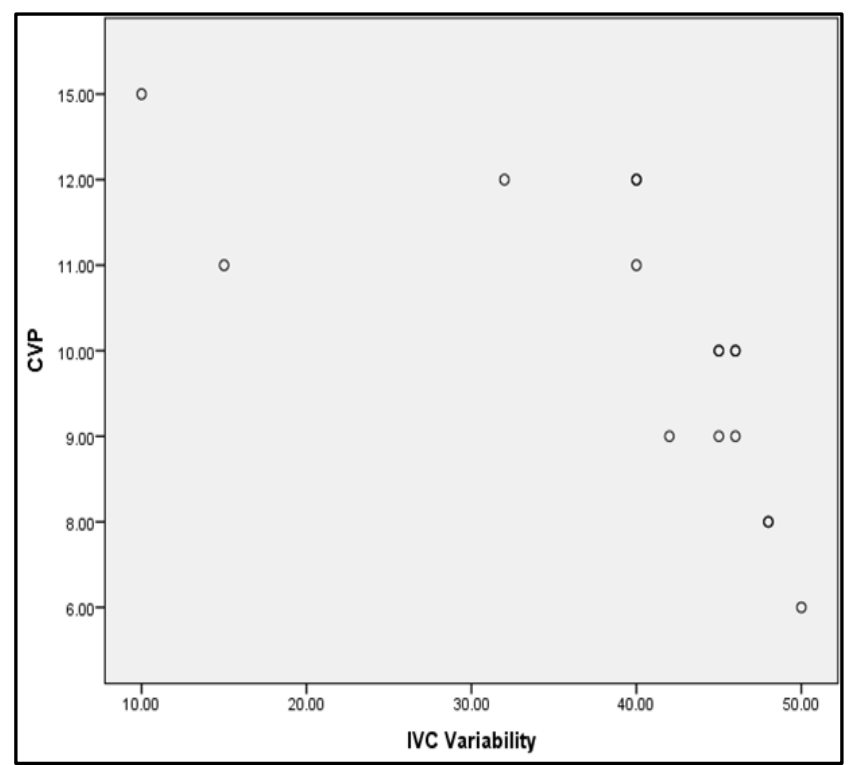

Graph 1. Pearson Correlation in CHF Negative Group

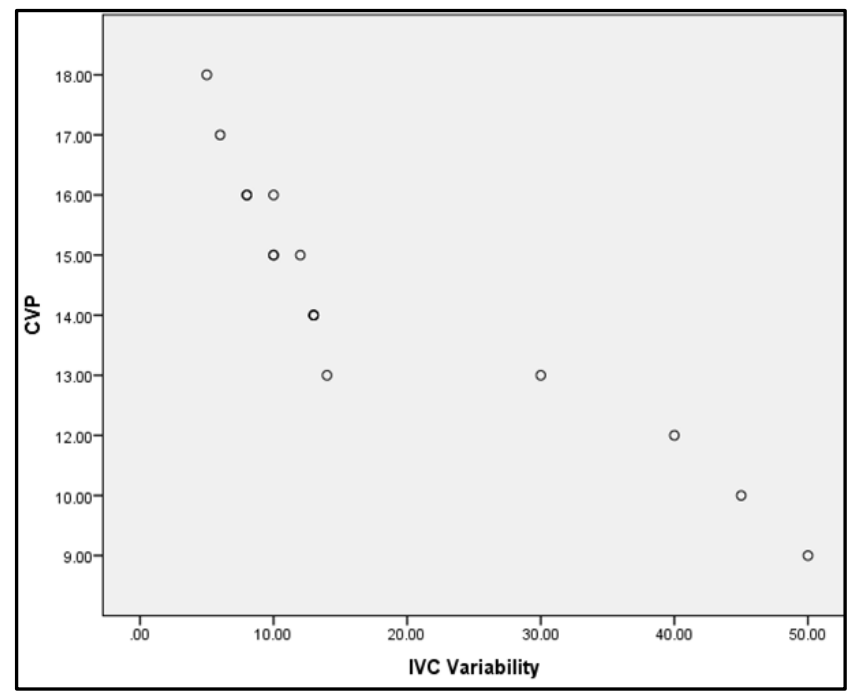

Graph 2. Pearson Correlation in CHF Positive Group

\section{DISCUSSION}

In a significant proportion of patients in intensive care unit, CHF complicates the course of illness and outcome. In ICU, CHF may present as a manifestation of newly diagnosed cardiac disease or as an exacerbation of underlying heart disease or a result of fluid overload or stress accompanying acute illness, surgery or trauma. Framingham's clinical criterion is used often to diagnose $\mathrm{CHF}$, but in critically ill patients these criteria are overlapped sometimes by other clinical conditions. Methods used to determine cardiac and intravascular volume status include central venous pressure and oxygen saturation monitors, pulmonary artery catheters, systemic arterial catheters, oesophageal Doppler monitors, transoesophageal echocardiography and TTE. Historically, these devices have been considered to be the standard in the management of critical illness but they are invasive, time consuming and resource intensive, and there is no consensus on their indication or accuracy.6-8 Invasive methods have potential morbidities associated with their use and several studies have suggested at best clinical equipoise and at worst increased mortality in patients exposed to invasive monitoring devices.9,10 For these reasons, the development of noninvasive tools and/or methods to estimate volume status and cardiac function is highly appealing. ${ }^{11}$

In this study, bedside echocardiography allowed an accurate assessment of LVEF when compared with the clinical parameters. This has advantage over standard echocardiography in being focused and rapid to perform. Previous studies have shown that physical examination was inaccurate in predicting the haemodynamic status of ICU patients when using right heart catheterisation as a reference. In these series cardiac index was adequately graded as low, normal or high in only approximately half of the cases when compared to measurements obtained by thermodilution technique.12,13 In a systematic review of literature, Badgett et al reported that the performance of the physical examination for detecting a decreased LVEF or increased LV filling pressure was fairly poor in ICU patients with an overall sensitivity and specificity of $54 \%$ and $69 \%$ respectively. ${ }^{14}$ 
Table 3 shows inferior vena cava diameter variability of patients in CHF positive and CHF negative groups. Out of total 14 CHF positive patients, IVC diameter variability was $<15 \%$ in $11(78.57 \%)$ patients, $16-40 \%$ in $1(7.14 \%)$ patients and was $>40 \%$ in $2(12.28 \%)$ patients. Out of total $16 \mathrm{CHF}$ negative patients, IVC diameter variability was < $15 \%$ in $1(6.25 \%)$ patients and $>40 \%$ in 15 (93.75\%) patients. Variability was significantly higher in CHF negative group ( $\mathrm{p}$ value $=<0.001$ ). It means $\mathrm{CHF}$ negative patients were more responsive to further fluid resuscitation.

De Vecchis et al 2012 in their study found that high right atrial pressures dilate the IVC and worsen the normal IVC collapsibility. According to their observations, congestion would be indicated by relatively small Inferior Vena Cava Collapsibility Index (IVCCI) values, while intravascular depletion would be revealed by wide fluctuations of IVC diameter, generating relatively high values of IVCCI. Therefore, small, collapsible IVC as visualised by echocardiography represents low right atrial pressures, whereas large, non-collapsible IVCs reflects high right atrial pressures. ${ }^{15,16}$ In the presence of marked volume overload, the respiratory cycle leads to minimal change of IVC, regardless of its absolute diameter. ${ }^{17}$ This depends on the peculiar nonlinear pressure diameter relationship of the IVC, so that above a threshold pressure (i.e. CVP > $20 \mathrm{mmHg}$ ), no further increase in IVC diameter can be observed. ${ }^{18}$ This has been confirmed by a recent study in which an IVCCI $<15 \%$ was highly sensitive and specific for the diagnosis of acute decompensated heart failure, whereas the absolute diameter of the IVC in itself was non-diagnostic. ${ }^{19}$

In other studies also ultrasonographic measurement of large respiratory variation of Inferior Vena Cava (IVC) diameter has been shown to correlate with volume depletion in patients with septic shock ${ }^{20}$ and also examined the utility of bedside echocardiographic measurement of the IVC as a marker of volume overload in patients with acute shortness of breath. We found that respiratory variation of the IVC was correlated with CVP in patients for diagnosis of CHF. Recent research in critical care has been shown that respiratory variation in IVC diameter can be used to predict volume responsiveness in patients with septic shock. ${ }^{20}$ Patients with wide variation in IVC diameter with respiratory cycle were found to be more responsive to fluid therapy than those with smaller variations.

The determinant of CHF in this study was clinical using Framingham's criteria. It may be argued that better reference standards for CHF are invasive measurements. However, it is not feasible in the clinical setting to subject all in hospital patients with suspected CHF to catheterisation and CHF is ultimately a clinical diagnosis. Furthermore, the Framingham's criteria were shown to be highly predictive (90\%) of elevated left ventricular filling pressure measured invasively with sensitivity of about $92 \%$ and moderate specificity of $80 \%{ }^{21}$

Our results suggest that bedside echocardiography is reliable to assess LVEF and IVC volume status during a short, focused examination in ICU patients. The range of indications is limited and the results of bedside echocardiography should be reported as part of the physical examination. Finally, a specific training and certification is recommended for all users. $^{22}$ In addition to the semi-quantitative evaluation of LVEF, the bedside echo appears promising to quickly evaluate in ICU patients the right ventricular size and function, the presence and volume of pericardial and pleural effusions as well as the size and respiratory variations of the inferior vena cava due to its two-dimensional imaging quality. In this study, echocardiographic examination was dependent on user's capability. Nevertheless, this potential methodological bias should have a minor impact on the observed results since bedside echo has been used in our ICU since quite some time. However, the present results cannot be generalised to less experienced operators.

Strength of this study includes its perspective nature and its patient composition. Prior studies in this field have limited enrolment to only mechanically ventilated patients, often with chemical paralysis. Before this study, limited information existed about the validity of static indices such as CVP or SI (Shock Index) to predict haemodynamic responsive to volume expansion in critically ill, spontaneous breathing patients or in patients with assisted modes of ventilation.

Limitations of this study include its small size. Other limitation is that we used echocardiography just once at the time of admission and hence we cannot judge the impact, echocardiography would have in prognosis and therapeutic decision if done serially on critically ill patients.

\section{CONCLUSION}

Bedside echocardiography provides the intensivists a mean to do fast and focused cardiac evaluation and estimation of volume status too. It offers a substitute to standard echocardiography done by cardiologists. Moreover, it is teachable and should become a part of future critical care curriculum.

So use of bedside echocardiography in critically ill patients for evaluating cardiac function and volume status is being recommended.

\section{REFERENCES}

1. Davis AP, Francis CM, Love MP, et al. Value of the electrocardiogram in identifying heart failure due to left ventricular systolic dysfunction. BMJ 1996;312 (7025):222.

2. Salem R, Vallee F, Rusca M, et al. Haemodynamic monitoring by echocardiography in the ICU: the role of the new echo techniques. Curr Opin Crit Care 2008;14(5): 5461-8.

3. Hüttemann E, Schelenz C, Kara F, et al. The use and safety of transoesophageal echocardiography in the general ICU- a minireview. Acta Anaesthesiol Scand 2004;48(7): 827-36.

4. Poelaert JI, Schüpfer G. Haemodynamic monitoring utilizing TEE: the relationships among pressure, flow and function. Chest 2005;127(1):379-90.

5. Charron C, Caille V, Jardin F, et al. Echocardiographic measurement of fluid responsiveness. Curr Opin Crit Care 2006;12(3):249-54.

6. Kumar A, Anel R, Bunnell E, et al. Pulmonary artery occlusion pressure and central venous pressure fail to predict ventricular filling volume, cardiac performance, or the response to volume infusion in normal subjects. Crit Care Med 2004;32(3):691-9. 
7. Shah MR, Hasselblad V, Stevenson LW, et al. Impact of the pulmonary artery catheter in critically ill patients: meta analysis of randomized clinical trials. JAMA 2005;294(13): 1664-70.

8. Binanay C, Califf RM, Hasselblad V, et al. Evaluation study of congestive heart failure and pulmonary artery catheterization effectiveness: the ESCAPE trial. JAMA 2005;294(13):1625-33.

9. Sandham JD, Hull RD, Brant RF, et al. Randomized, controlled trial of the use of pulmonary-artery catheters in high risk surgical patients. N Engl J Med 2003;348(1):5-14.

10. Richard C, Warszawski J, Anquel N, et al. Early use of pulmonary artery catheter and outcomes in patients with shock and acute respiratory distress syndrome: a randomized controlled trial. JAMA 2003;290(20):2713-20.

11. Shoemaker WC, Wo CC, Chien LC, et al. Evaluation of invasive and noninvasive hemodynamic monitoring in trauma patients. J Trauma 2006;61(4):844-53.

12. Connors AF, McCaffree DR, Gray BA. Evaluation of right heart catheterization in critically ill patient without acute myocardial infarction. N Eng J Med 1983;308(5):263-267.

13. Eisenberg PR, Jaffe AS, Schuster DP. Clinical evaluation compared to pulmonary artery catheterization in haemodynamic assessment of critically ill patients. Crit Care Med 1984;12(7):549-53.

14. Badgett RG, Lucey CR, Mulrow CD. Can the clinical examination diagnose left sided heart failure in adults? JAMA 1997;277(21):1712-19.

15. De Vecchis R, Ciccarelli A, Ariano C, et al. Inferior vena cava collapsibility and heart failure signs and symptoms: new insight about possible links. Arq Bras Cardiol 2012;98(6): 544-52.
16. Kircher BJ, Himelman RB, Schiller NB. Noninvasive estimation of right atrial pressure from the inspiratory collapse of inferior vena cava. Am J Cardiol 1990;66(4): 493-6.

17. Moreno FL, Hagan AD, Holmen JR, et al. Evaluation of size and dynamics of the inferior vena cava as an index of rightsided cardiac function. Am J Cardiol 1984;53(4):579-85.

18. Jardin F, Barbier C, Baron VA. Respratory changes in inferior vena cava diameter are helful in predicting in fluid responsiveness in ventilated septic patients. Intensive Care Med 2004;30(9):1740-6.

19. Blehar DJ, Dickman E, Gaspari R. Identification of congestive heart failure via respiratory variation of inferior vena cava diameter. Am J Emerg Med 2009; 27(1): 71-5.

20. Feissel M, Michard F, Faller JP, et al. The respiratory variation in inferior vena cava diameter as a guide to fluid therapy. Intensive Care Med 2004;30(9):1834-7.

21. Zile MR, Gaasch WH, Carroll JD, et al. Heart failure with a normal ejection fraction: is measurement of diastolic function necessary to make the diagnosis of diastolic heart failure ? Circulation 2001;104(7):779-82.

22. Sicari R, Galderisi M, Voigt JU, et al. The use of pocket-size imaging devices: a position statement of the European association of echocardiography. Eur J Echocardiogr 2011; 12(2):85-7. 